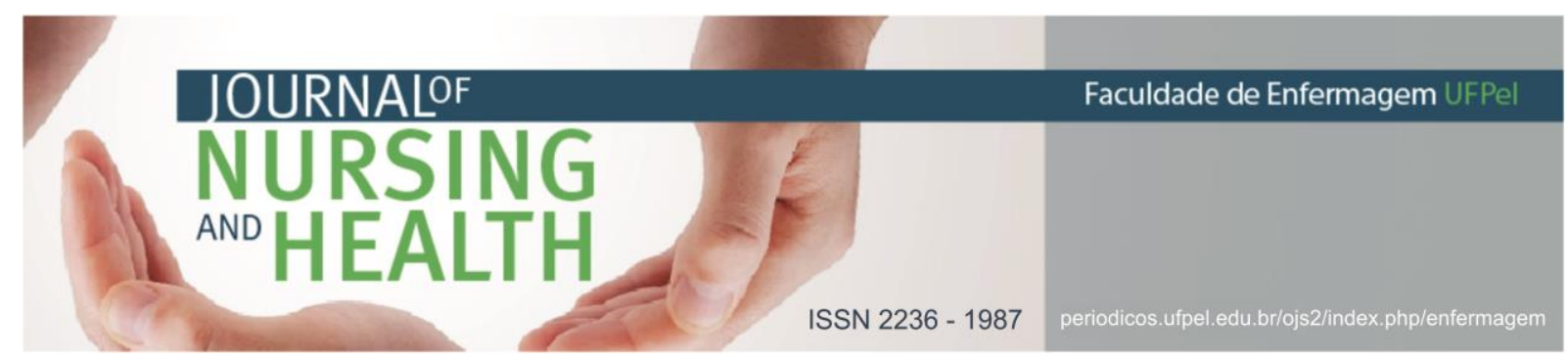

ARTIGO ORIGINAL

\title{
Competências desenvolvidas por equipe de saúde da família sobre o acolhimento após atividade educativa
}

\author{
Competencies developed by a family health team about user welcoming after \\ educational activity
}

\section{Competencias desarrolladas por equipo de salud de familia acerca del acogimiento después de actividad educativa}

\author{
Isabel Cristina HENTGES ${ }^{1}$; Ana Luísa Petersen $\mathrm{COGO}^{2}$
}

\begin{abstract}
RESUMO
Objetivo: identificar o conhecimento, as habilidades e as atitudes sobre acolhimento desenvolvidas por uma Equipe de Saúde. Métodos: pesquisa qualitativa do tipo estudo de caso realizado com 13 profissionais de uma Equipe de Saúde da Família após terem participado de atividade educativa em 2013 sobre o tema acolhimento. Os dados foram obtidos por entrevista grupal e analisados pela análise de conteúdo temática. Projeto aprovado por Comitê de Ética em Pesquisa (CAAE 12552613.6.0000.5347). Resultados: nas falas dos participantes emergiram os temas: 'conhecimento sobre acolhimento', 'atitudes sobre o acolhimento' e 'habilidades sobre o acolhimento'. Considerações Finais: o estudo sinalizou a importância de fortalecer as competências do acolhimento envolvendo todos, os membros da Equipe de Saúde da Família.

Descritores: Enfermagem; Acolhimento; Atenção primária à saúde; Educação em enfermagem.
\end{abstract}

\section{ABSTRACT}

Objective: to analyze the competencies about user embracement developed by a Family Health Team after their participation in an online course. Methods: qualitative case study developed with 13 professionals of a Family Health Team that participated in an online course about user embracement. The data was collected through group interview and analyzed using the thematic analysis technique. Research Ethics Committee (CAAE 12552613.6.0000.5347) approved this study. Results: In the participants, speeches emerged the themes 'knowledge of user embracement', 'attitudes of user embracement', 'skills for user embracement'. Final Considerations: this study has shown the importance of rethink about the user embracement competencies in the Family Health Team context. Descriptors: Nursing; User embracement; Primary health care; Nursing, Education.

\section{RESUMEN}

Objetivo: analizar las competencias sobre la acogida desarrolladas por un Equipo de Salud de la Familia después de participar en curso en línea. Métodos: estudio cualitativo del tipo estudio de caso fue realizado con 13 profesionales de un Equipo de Salud de la Familia que participaron de curso en línea sobre la acogida. Los datos fueron recogidos mediante entrevistas grupales y se analizaron mediante análisis de contenido temático. El estudio fue aprobado por Comité de Ética en Investigación (CAAE 12552613.6.0000.5347). Resultados: y los discursos de los participantes surgió los temas 'conocimiento de acogida', actitudes de acogida' y 'habilidades de acogida'. Consideraciones Finales: e este estudio se señaló la importancia de repensar la realización del acogimiento en los contextos de los Equipos de Salud de Familia.

Descriptores: Enfermería; Acogimiento; Atención primaria de salud; Educación en enfermería.

\footnotetext{
${ }^{1}$ Enfermeira. Mestre em Enfermagem. Enfermeira do Instituto Municipal de Estratégia de Saúde da Família, Porto Alegre, RS, Brasil. Email: isabel.hentges@gmail.com.

${ }^{2}$ Enfermeira. Doutora em Enfermagem. Universidade Federal do Rio Grande do Sul, Porto Alegre, RS, Brasil. Email: analuisa@enf.ufrgs.br.
} 


\section{IOURNAIOF

O acolhimento é uma das principais diretrizes da Política Nacional de Humanização do Sistema Único de Saúde no Brasil com o propósito de reorientar o modelo tecnoassistencial e a atenção multidisciplinar na Atenção Básica em Saúde. ${ }^{1}$ A proposta do acolhimento pretende modificar 0 atendimento prestado ao usuário a partir da não distribuição de fichas, permitindo o acesso em qualquer momento durante o funcionamento da unidade de saúde a partir da mudança nas ações em saúde e do processo de trabalho das equipes. As ações em saúde derivadas do acolhimento pretendem assegurar o acesso de forma ética e resolutiva às necessidades do usuário em consonância com os recursos da comunidade. $^{2}$

As tecnologias leves, como as relacionais e as de vínculo, subsidiam a concepção de cuidado ampliado que orienta as ações do acolhimento. ${ }^{2}$ Neste contexto, a equipe de enfermagem, enquanto integrante da Equipe de Saúde da Família, tem um protagonismo ao ser, na maioria das vezes, a responsável pelo primeiro contato com o usuário. No cotidiano da Atenção Básica percebe-se que os demais profissionais nem sempre possuem o entendimento de que 0 acolhimento é corresponsabilidade de toda a Equipe de Saúde da Família e deve ser realizado durante todo o período de funcionamento do serviço de saúde. Desta forma, percebe-se que existe um distanciamento entre 0 cuidado preconizado e a realidade do atendimento realizado pela unidade de saúde.
A falta de recursos humanos e materiais, as dificuldades de organização do processo de trabalho, o despreparo profissional para o trabalho em equipe e a falta de qualificação são apontados como fatores que interferem no processo de trabalho das Equipes de Saúde da Família, buscando implementar o acolhimento no seu cotidiano. $^{3}$ Esta proposta de atendimento proporciona uma aproximação maior entre os trabalhadores de saúde e os usuários, o que gera resistências e tensionamentos. ${ }^{4}$

O acolhimento não está sendo realizado de forma uniforme na atenção básica, havendo a necessidade de cada serviço compreender as suas singularidades e as particularidades do território de atuação para propor a implantação dos princípios norteadores da Política de Humanização do Sistema Único de Saúde (SUS). ${ }^{5}$ A prática profissional deve focar na humanização e não nas rotinas de serviço; para as mudanças no atendimento é que a educação permanente pode contribuir de forma decisiva. ${ }^{5}$

As ações de educação permanente e a análise dos processos de trabalho na Atenção Básica são as possibilidades de apresentar e discutir os referenciais da Política Nacional de Humanização que orientam a prática do acolhimento, viabilizando a sua implantação. ${ }^{6}$ Neste contexto, a educação permanente vem proporcionar um espaço nos serviços de saúde para o aprofundamento teórico-prático e a discussão dos processos de trabalho, diferentemente 


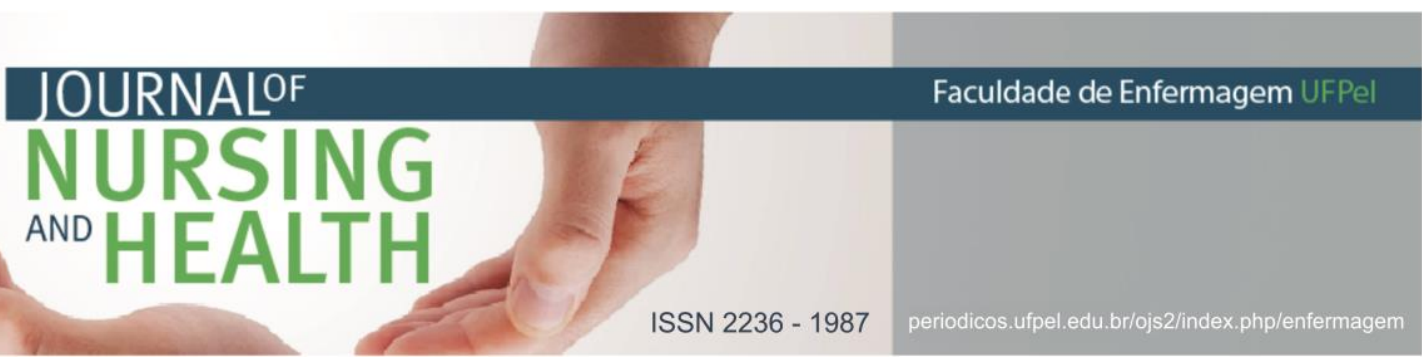

do que ocorre nos treinamentos ou nas capacitações tradicionais. ${ }^{4}$

As ações de educação permanente têm como propósito realizar uma reflexão crítica sobre as práticas profissionais contextualizada no local de trabalho. No Brasil existem estratégias que colaboram nesse movimento de qualificar a educação no ambiente de trabalho do SUS, entre eles pode ser citada a Universidade Aberta do SUS (UMA_SUS). ${ }^{7}$ Nessa proposta, que tem como foco 0 aperfeiçoamento na atenção básica, é utilizada a modalidade a distância como um recurso que possibilita a acessibilidade dos profissionais. ${ }^{7}$

A complexidade que envolve o processo de trabalho realizado na Atenção Básica fez com que Organização Panamericana da Saúde propusesse em 2010 o Marco Regional de Competências Essenciais em Saúde Pública, proposta que visa fortalecer os sistemas de saúde e aprimorar os recursos humanos. ${ }^{6}$ As competências são entendidas como conhecimentos, habilidades e atitudes necessárias para o desenvolvimento de um profissional ético que desempenhe suas atribuições com qualidade. ${ }^{4,6}$ Ainda se faz necessário aprofundar a discussão e a avaliação das competências específicas para as ações realizadas na atenção básica, como por exemplo o acolhimento.

Considerando a abrangência das competências necessárias para as ações na Atenção Básica propôs-se como questão de pesquisa neste estudo quais seriam os conhecimentos, habilidades e atitudes que os profissionais desta equipe de saúde da

família considerariam necessários para a realização do acolhimento.

A presente investigação surgiu das reflexões que ocorreram durante a implantação de uma Unidade de Saúde da Família, na qual os profissionais tinham questionamentos sobre o tema acolhimento, sinalizando a necessidade de reverem a Política Nacional de Humanização. Assim, foi proposta uma atividade educativa em serviço com atividades na modalidade a distância e presenciais. Esta atividade possibilitou a análise dos referenciais teóricos que fundamentam as ações na Atenção Básica, a troca de saberes entre os profissionais, o conhecimento entre membros da equipe que tinham pouco convívio e o despertar de reflexões sobre o processo de trabalho no que se refere ao acolhimento. ${ }^{8}$

O objetivo do presente estudo foi identificar o conhecimento, as habilidades e as atitudes necessárias para a realização do acolhimento desenvolvidas por uma Equipe de Saúde da Família após a participação em atividade educativa. A relevância da presente pesquisa reside no fato de contribuir com a discussão do processo de trabalho das Equipes de Saúde da Família, especialmente no que se refere ao acolhimento e à educação em serviço na Atenção Básica.

\section{MÉTODO}

Esta pesquisa de caráter qualitativo se caracterizou como um estudo de caso $^{9}$, com o propósito de conhecer o contexto vivenciado por uma equipe de saúde da família sobre a prática do acolhimento após a 


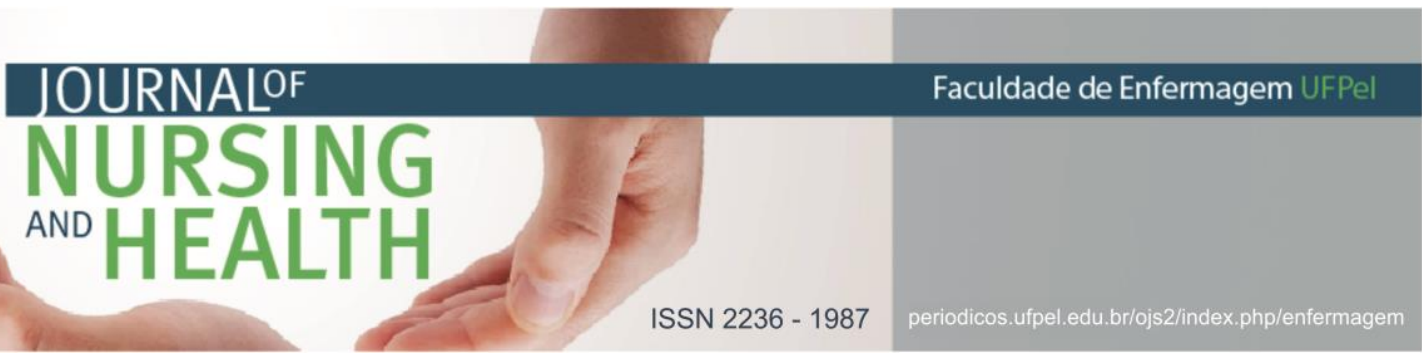

participação em atividade de educação em serviço envolvendo o tema. 0 campo de estudo foi uma Unidade de Saúde da Família localizada na cidade de Porto Alegre, que executava suas atividades a partir de uma entidade filantrópica na prestação de serviço complementar ao Sistema Único de Saúde, em convênio firmado com a Secretaria Municipal de Saúde. Esta Equipe contava com uma política institucional de educação em serviço dispondo dos recursos necessários para tal fim, como internet e equipamento de informática no ambiente de trabalho.

A população foi composta de 21 profissionais que integravam a Equipe de Saúde da Família, formada por agentes comunitários de saúde, auxiliar administrativo, auxiliar em saúde bucal, enfermeiros, médicos, odontólogo, técnicos de enfermagem e técnico em saúde bucal. Os critérios de inclusão foram: ser profissional da equipe de saúde, independentemente do tempo de trabalho, que realizasse orientações e atendimentos aos usuários do Sistema Único de Saúde, desde o funcionamento da unidade até os fluxos do sistema de saúde, orientando sobre os atendimentos médicos, de enfermagem e de saúde bucal, realizadas nas visitas domiciliares e/ou na própria unidade. Foram excluídos aqueles profissionais que: possuíam regime de trabalho mensal inferior a 220 horas na equipe de saúde; estavam em férias ou afastados por qualquer motivo. Dessa forma, a amostra foi constituída por conveniência, totalizando 13 participantes.
A atividade educativa intitulada “Acolhimento na Atenção Básica: uma prática constitutiva das ações em saúde" foi proposta à equipe de saúde após uma consulta verbal sobre a escolha da temática que consideravam relevante para ser discutida pelo grupo. A proposta objetivou que todos os profissionais desta unidade de saúde pudessem obter fundamentações teóricas e discutir o acolhimento, utilizando o ambiente virtual de aprendizagem Moodle, ou presencialmente, durante dois meses (novembro e dezembro de 2013), totalizando 12,5 horas. Foram propostos três módulos com atividades de leitura, disponibilização de vídeos, discussão em fórum, além de estudos de casos elaborados pelos participantes e discutido entre eles. ${ }^{8}$

A coleta de dados ocorreu após a conclusão desta atividade educativa, em dezembro de 2013, com duas entrevistas de grupo realizadas em dois momentos, com sete participantes em cada uma. As entrevistas contaram com um moderador, um observador e um relator. Os grupos foram organizados de maneira a contarem com diferentes profissionais, havendo heterogeneidade para que ocorressem os debates e a diversidade de pontos de vista. As questões norteadoras das entrevistas foram construídas a partir do referencial teórico de competências ${ }^{10}$ : quais conhecimentos forma adquiridos nesta atividade educativa sobre acolhimento na Atenção Básica; quais foram as habilidades desenvolvidas sobre 0 acolhimento; quais foram as atitudes desenvolvidas sobre 0 acolhimento após a participação na atividade educativa e quais foram as 


\section{NURSING \\ AND}

repercussões no atendimento aos usuários da unidade de saúde que ocorreram após as discussões na atividade educativa.

As informações da entrevista de grupo foram transcritas, organizadas e processadas com o software Nvivo9. 0 anonimato foi assegurado com a designação Participante 1, Participante 2 e assim sucessivamente. A técnica utilizada foi a análise temática com as seguintes etapas: organização do material coletado; construção das categorias descritivas iniciais, orientadas pelo referencial teórico; desvelamento dos sentidos implícitos e contraditórios; reagrupamento das categorias, procurando observar tendências e padrões; e busca de relações e inferências em nível de abstração mais elevado. ${ }^{9}$

0 projeto de pesquisa foi submetido ao Comitê de Ética da Universidade e da Instituição de Saúde na qual foi realizado o estudo, sendo o mesmo aprovado (CAAE 12552613.6.0000.5347). Os participantes assinaram o Termo de Consentimento Livre e Esclarecido, que assegurou $o$ anonimato e o respeito, assim como a liberdade de desistirem de participar da pesquisa a qualquer momento, em atendimento às recomendações da Resolução $466 / 2012$, que regulamenta a pesquisa envolvendo seres humanos. ${ }^{11}$ Os arquivos com as gravações e as transcrições das entrevistas foram armazenados e serão destruídos após 5 anos.
ISSN 2236 - 1987

\section{RESULTADOS E DISCUSSÃO}

Os profissionais participantes deste estudo expressaram em suas falas as competências desenvolvidas, as quais serão apresentadas em três temas: 'conhecimento sobre acolhimento', 'atitudes sobre o acolhimento' e 'habilidades sobre o acolhimento'. Para a composição dos temas considerou-se como 'conhecimento' os saberes teóricos adquiridos ou não na atividade educativa, ou a que os profissionais poderiam fazer referência, como por exemplo a Política de Humanização do SUS. As 'atitudes' referiram-se aos comportamentos relatados pelos participantes no momento que estivessem em situações de realização do acolhimento. As 'habilidades' referem-se ao saber-fazer o acolhimento, integrando o conhecimento com a prática profissional. Essa caracterização foi construída com base no referencial teórico do estudo, adaptando-o ao contexto do acolhimento na atenção básica. ${ }^{10}$

0 'conhecimento sobre acolhimento' referiu-se à troca de saberes entre os diferentes profissionais da equipe, agregando saberes novos aos adquiridos anteriormente. A atividade educativa oportunizou aos profissionais explorarem materiais bibliográficos e a conhecerem relatos de outras equipes de saúde da família na implantação do acolhimento.

Acredito que eu já tenha recebido os conteúdos nos cadernos de saúde, mas não sentei e li de ponta a ponta [...] 


\section{JOURNALOF \\ NURSING \\ AND}

ISSN 2236 - 1987

[...] em relação ao acolhimento, é uma coisa que a gente vive o tempo todo, que se luta para colocar em prática e é tão difícil. A população não conhece, é uma coisa nova para população e talvez até para muitos trabalhadores da área da saúde (Participante 1).

A falta de conhecimento dos

[...] Tinha artigos que a gente até imprimiu pra ter e poder ler, que relatavam casos de outras equipes de saúde da família até fora do nosso Estado. Eu achei bem importante ver esse conhecimento que tem fora daqui (Participante 8).

Os profissionais da equipe de saúde da família reconheceram a importância de participarem da atividade educativa para repensarem a prática, reconhecendo a provisoriedade do conhecimento e a necessidade de reverem o atendimento que têm realizado. 0 debate sobre 0 acolhimento e a humanização do atendimento somente ocorrem se houver um aprofundamento da discussão sobre o processo de trabalho na atenção básica possibilitada pela educação permanente. ${ }^{12}$

Neste movimento de discussão sobre o acolhimento e as diretrizes que o orientam há a constatação dos profissionais de que os usuários desconhecem o funcionamento do sistema de saúde. Os profissionais não se sentem seguros em como proceder quando são abordados pelos usuários, não conseguindo colocar em prática ações em saúde voltadas à melhoria do acesso, ao vínculo e a mudanças nos processos de trabalho. usuários sobre 0 propósito do acolhimento confirma a constatação de que existe uma expectativa da população em obter uma resolutividade imediata dos serviços de saúde frente às suas necessidades. A avaliação da implantação da humanização no atendimento na rede de Atenção Básica em cidades como Campinas e Salvador mostrou a importância da discussão sobre o processo de trabalho e do esclarecimento dos usuários. ${ }^{13-14}$ Dessa forma, reitera-se a importância da participação popular nos fóruns de discussão municipais sobre a organização e o funcionamento dos serviços de saúde.

No tema 'habilidade no acolhimento' foram descritas a prática e os procedimentos relacionados à execução do mesmo, caracterizando o saber-fazer. Nos relatos dos participantes o cotidiano do serviço de saúde é apresentado como algo instituído, mas estes nem sempre se sentem preparados para a realização do acolhimento e consequentemente encontram dificuldades para a execução do mesmo.

[...] a pessoa é acolhida. O paciente é acolhido assim que ele chega na unidade, ele é recebido pela gente que está na porta. 


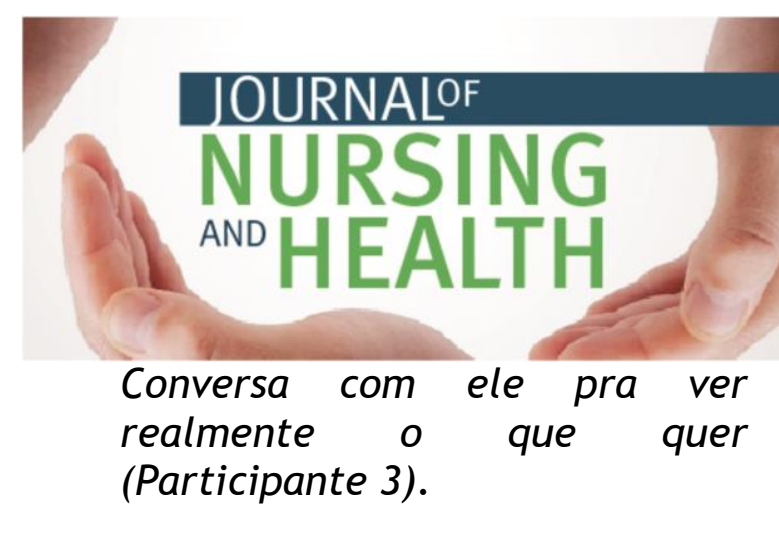

[...] não é simplesmente a Secretaria querer que os postos façam acolhimento, porque a Secretaria vai dizer que o seu médico está lá das $8 \mathrm{~h}$ às $17 \mathrm{~h}$ pra the atender [...] (Participante 7).

Como vamos fazer para acolher a todos? [...] a gente tem muita dificuldade com os usuários. Eles eram atendidos num outro modelo que não era o acolhimento [...] Todos os dias a gente reforça o que é o acolhimento, como é o funcionamento do serviço, que muitos não vão ser atendidos pelo médico (Participante 12).

$\mathrm{Na}$ fala do Participante 12 foi retratada a dificuldade encontrada para organizar $\mathrm{o}$ atendimento da demanda espontânea que busca a consulta médica. 0 questionamento dos profissionais desta unidade de saúde da família foi sobre como fazer para acolher todos os usuários nas suas necessidades sem que isto cause um conflito, pois muitos não compreendem que acolher não significa necessariamente ser atendido pelo médico imediatamente. A classificação de risco, que já estava sendo realizada pela equipe do estudo, visa garantir o acesso com a adoção de critérios que possam avaliar as vulnerabilidades e as situações de urgência, respaldando o profissional de saúde na tomada de decisão. ${ }^{15-17}$

A consolidação da Estratégia Saúde da Família é o objetivo que pretende reorganizar a atenção básica,
ISSN 2236 - 1987

a qual se caracteriza por uma assistência a saúde que ocorre tanto no âmbito individual quanto no coletivo, que busca a promoção e proteção da saúde, prevenção de agravos, incluindo o diagnóstico, tratamento, reabilitação e redução de danos, tendo ainda um enfoque na manutenção da saúde dos usuários. Neste modelo de atenção, a atuação interdisciplinar e em equipe valoriza os diversos saberes e práticas na perspectiva de uma abordagem integral e resolutiva, com acompanhamento e avaliação sistemática das ações implementadas. ${ }^{18}$

A atenção básica, para contribuir para o adequado funcionamento da Rede de Atenção à Saúde, deveria ser o primeiro ponto de atenção e principal porta de entrada do sistema; ser resolutiva a partir da identificação de riscos e necessidades; e ainda ordenadora da rede, organizando as necessidades de saúde de sua população em relação aos outros pontos da rede. ${ }^{18}$ Como foi referido pelos participantes do estudo, a expectativa do usuário pela consulta médica é muito forte e esse seria um dos conflitos presentes no momento do acolhimento. Isso evidencia que a porta de entrada do sistema, que deveria ser resolutiva e acolhedora não está conseguindo dar conta da demanda existente.

0 tema 'atitude sobre o acolhimento' ficou caracterizado nas falas dos participantes ao demonstrarem intenção de modificar e melhorar o atendimento aos usuários. A avaliação do processo de trabalho torna-se uma necessidade de determinação dos objetivos a que se 


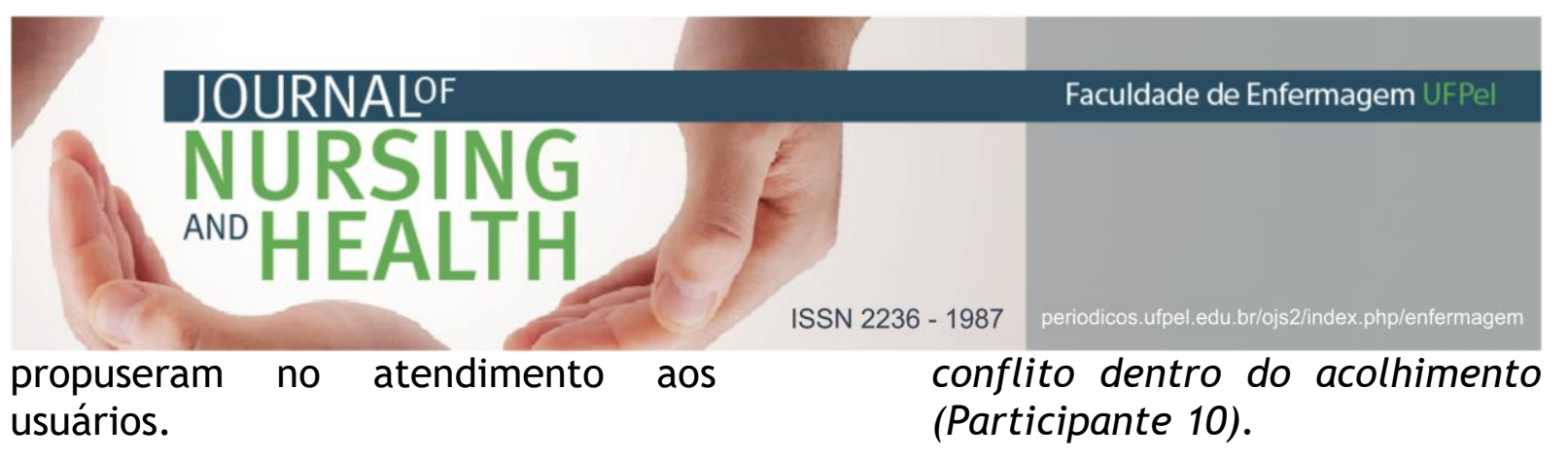

$[. .$.$] a reflexão às vezes nos$
coloca no prumo de novo $[. .$.
algumas modificações de
pequenas atitudes $[.$.
(Participante 5$).$

[...] depois lendo o material [...] vi que a gente estava fazendo o correto, mas que pode acrescentar mais [...] Modificar, trabalhar, melhorar, porque achava que já era o suficiente (Participante 6).

Colocar o acolhimento em prática requer uma reorganização do serviço de saúde a partir da problematização do processo de trabalho, na qual as atividades possam ser compartilhadas entre todos os profissionais. Para que essa problematização ocorra, é necessária uma maior capacidade de análise, intervenção e autonomia para estabelecer práticas transformadoras no processo de trabalho, aproximando a concepção da execução do trabalho a partir das necessidades de saúde da população. ${ }^{18}$

A atitude do profissional ao reconhecer a necessidade do usuário e buscar a resolução desse problema está presente nas falas dos participantes. No entanto, a realização do acolhimento não ocorre sempre de forma tranquila havendo tensionamentos nas relações entre os usuários e os profissionais.

[...] a gente precisa conversar, acolher, ouvir o paciente. E aí em algumas situações se torna um desafio e vêm as situações de
0 atendimento centrado no usuário necessita da organização do processo de trabalho da equipe de saúde, além de área física adequada para realizar 0 acolhimento que assegure o acesso e ambiente com privacidade.19 Outro aspecto que merece ser destacado é a importância do apoio ao profissional da equipe de saúde da família para que esteja preparado para enfrentar situações de conflito que podem gerar sofrimento no trabalho e frustrações pela falta de resolutividade ou de materiais para garantir um cuidado com qualidade. 20

Nas falas dos participantes deste estudo constata-se que há entendimento de que o acolhimento irá ampliar o acesso ao serviço de saúde. No entanto, os usuários não possuem clareza nessa proposta, pois ser acolhido não garante a consulta médica. A dicotomia existente é entre a distribuição de fichas e o acolhimento, sendo que nesse último o acesso será baseado nas necessidades do usuário e fundamentado na classificação de risco realizada pelos profissionais.

A presença de diferentes profissionais em uma equipe de saúde, com diferentes saberes, enriquecem o campo comum de competências e consequentemente ampliam a capacidade de cuidado de toda a equipe. Com essa capacidade aumentada a partir de um cuidado compartilhado, o processo de trabalho centrado em procedimentos e nos profissionais desloca-se para um processo centrado no usuário, onde o cuidado deste é que irá nortear o 


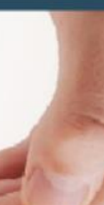

processo de trabalho da equipe.18 $\mathrm{E}$ estando o serviço de saúde organizado para acolher, escutar e oferecer uma resposta positiva, capaz de resolver grande parte dos problemas de saúde da população ou diminuir danos e sofrimentos, poderá ampliar os vínculos entre profissionais de saúde e usuários.18 Esse vínculo baseado nas relações de confiança e afetividade poderá ainda aprofundar o processo de corresponsabilização pela saúde, buscando desenvolver no usuário o sentimento de pertencimento ao cuidado prestado, trazendo sentido às ações em saúde propostas pela equipe, além do potencial terapêutico que pode provocar.

A educação permanente vem a contribuir com a formação dos profissionais para a realização do acolhimento no contexto de equipe multidisciplinar. Os participantes tiveram a possibilidade de refletir sobre o processo de trabalho de forma singular no contexto do território que atuam, situação essa recomendada em outro estudo. 5

0 desenvolvimento de competências na educação permanente permite que os profissionais de saúde tenham contato com a diversidade de conhecimentos existentes, refletindo sobre 0 cotidiano e problematizando, buscando a formação multidimensional fundamentada nas perspectivas do trabalho e da integralidade da atenção em saúde. Esta tem se constituído como uma das alternativas possíveis de mudanças nos espaços de trabalho, instigando a participação ativa dos envolvidos no processo, destacando
ISSN $2236-1987$

ainda a capacidade crítica dos sujeitos. ${ }^{4}$

Da mesma forma, a experiência compartilhada pelo UNA-SUS vem evidenciando os benefícios deste sistema de apoio à educação permanente dos trabalhadores de saúde, com o acesso mais amplo e moderno às informações em saúde, resultando em um cuidado cada vez mais qualificado. ${ }^{7}$

\section{CONSIDERAÇÕES FINAIS}

Este estudo pretendeu identificar as competências, entendidas como o conhecimento, as habilidades e as atitudes, desenvolvidas por uma Equipe de Saúde da Família após participação em uma atividade educativa sobre acolhimento. 0 trabalho desempenhado pelo profissional de saúde, observando os pressupostos do acolhimento, é complexo e exige habilidades de escuta, diálogo, vínculo e confiança estabelecidas com o usuário.

Os conhecimentos e as atitudes dos profissionais da equipe de saúde da família para o desenvolvimento do acolhimento levam a mudanças no processo de trabalho, que necessitam ser discutidas na equipe envolvida. Essas mudanças se referem ao comprometimento de todos os profissionais pela realização do acolhimento, além do entendimento do que isso significa e como irá repercutir no atendimento ao usuário.

No tema 'conhecimento sobre o acolhimento' os participantes destacaram a importância de tomarem parte da atividade educativa para 


\section{JOURNALOF \\ NURSING \\ NNOHEALTH}

ISSN 2236 - 1987

em que se produz a educação em serviço de Equipes de Saúde da Família, proporcionando o trabalho em grupo e a discussão do cotidiano de trabalho.

\section{REFERÊNCIAS}

1. Ministério da Saúde (BR). SecretariaExecutiva. Núcleo Técnico da Política Nacional de Humanização. HumanizaSuS: Política Nacional de Humanização: a humanização como eixo norteador das práticas de atenção e gestão em todas as instâncias do SUS. Brasília; 2004.

2. Silva TF, Romano VF. O acolhimento e o Núcleo de Apoio à Saúde da Família no município do Rio de Janeiro: fragmentos, perspectivas e reflexões. Rev bras med fam comunidade. 2015 $\mathrm{jan} / \mathrm{mar} ; 10(34): 1-7$.

3. Marques-Ferreira ML, BarreiraPenques RM, Sanches-Marin MJ. Acolhimento na percepção dos enfermeiros da Atenção Primária à Saúde. Aquichan. 2014;14(2): 216-25.

4. Salum NC, Prado ML. A educação permanente no desenvolvimento de competências dos profissionais de enfermagem. Texto contexto enferm. 2014; 23(2):301-8.

5. Coutinho LRP, Barbieri AR, Santos MLM. Acolhimento na Atenção Primária à Saúde: revisão integrativa. Saude em debate.2015; 39(105):514-24.

6. Suárez Conejero J, Godue C, García Gutiérrez JF, Magaña Valladares L, Rabionet S, Concha J, et al. Competencias esenciales en salud pública: un marco regional para las 


\section{JOURNALOF \\ NURSING \\ AND}

ISSN 2236 - 1987

Américas. Rev panam salud publica. 2013;34(1):47-53.

7. Oliveira VA, Nascimento EM, Franco SM, Brasil LSB, Lobo LCG. Constituição e expansão da rede UNA-SUS: trajetória 2008 a 2015. In: Gusmão CMG et al (org.). II relato de experiências em tecnologias educacionais do sistema UNA-SUS 2015. Recife: Ed universitária da UFPE; 2016. p.15-35.

8. Hentges IC, Cogo ALP. Existe um bom momento para fazer uma atualização em serviço? In: Ferla AA et al editores. Cadernos da Saúde Coletiva. Redes Vivas de Educação e Saúde: relatos e vivências da integração universidade e sistema de saúde. 1 ed. Porto Alegre: Editora Rede Unida; 2015. p.175-81.

9. Ludke M, André MED. A Pesquisa em Educação: abordagens qualitativas. 14 Reimpressão. São Paulo: Editora EPU; 2012.

10. Sacristán JG, Pérez Goméz Al, Rodríguez JBM, Santomé JT, Rasco FA, Méndez JMA. Educar por competências: o que há de novo? $1^{\text {a }}$ Edição. Porto Alegre: Artmed; 2011.

11. Ministério da Saúde (BR). Conselho Nacional de Saúde. Resolução 466, de 12 de dezembro de 2012: diretrizes e normas regulamentadoras de pesquisa envolvendo seres humanos. Brasília; 2012.

12. Nora CRD, Junges JR. Política de humanização na atenção básica: revisão sistemática. Rev saúde pública. 2013;47(6):1186-200.

13. Takemoto MLS, Silva EM. Acolhimento e transformações no processo de trabalho de enfermagem. Cad saúde pública. 2007; 23(2):331-40.

14. Vieira-da-Silva LM, Esperidião MA, Viana SV, Alves VS, Lemos DVS, Caputo MC, et al. Avaliação e monitoramento da implantação de um programa voltado para melhoria da acessibilidade e humanização do acolhimento aos usuários na rede básica. Salvador, 2005-2008. Rev bras saúde matern infant. 2010; 10 Suppl:S131-43.

15. Ministério da Saúde (BR). Secretaria de Atenção à Saúde. Departamento de Atenção Básica. Cadernos de Atenção Básica n. 28, Volume I: Acolhimento à Demanda Espontânea. Brasília; 2011.

16. Mitre SM, Andrade EIG, Cotta RMM. Avanços e desafios do acolhimento na operacionalização e qualificação do Sistema Único de Saúde na Atenção Primária: um resgate da produção bibliográfica do Brasil. Ciênc saúde colet. 2012; 7(8):2071-85.

17. Chagas HMA, Vasconcelos MPC. Quando a porta de entrada não resolve: análise das unidades de saúde da família no município de Rio Branco, Acre. Saúde soc. 2013;22(2):377-88.

18. Brasil. Portaria no 2.488 de 21 de outubro de 2011. Aprova a Política Nacional de Atenção Básica, estabelecendo a revisão de diretrizes e normas para a organização da Atenção Básica, para a Estratégia Saúde da Família (ESF) e o Programa de Agentes Comunitários de Saúde (PACS). Diário Oficial da União. Seção 1. 21 out 2011.

19. Ribeiro JP, Mamed SN, Souza MR, Souza MM, Rosso CFW. Acessibilidade aos serviços de saúde na Atenção Básica do Estado de Goiás. Rev 


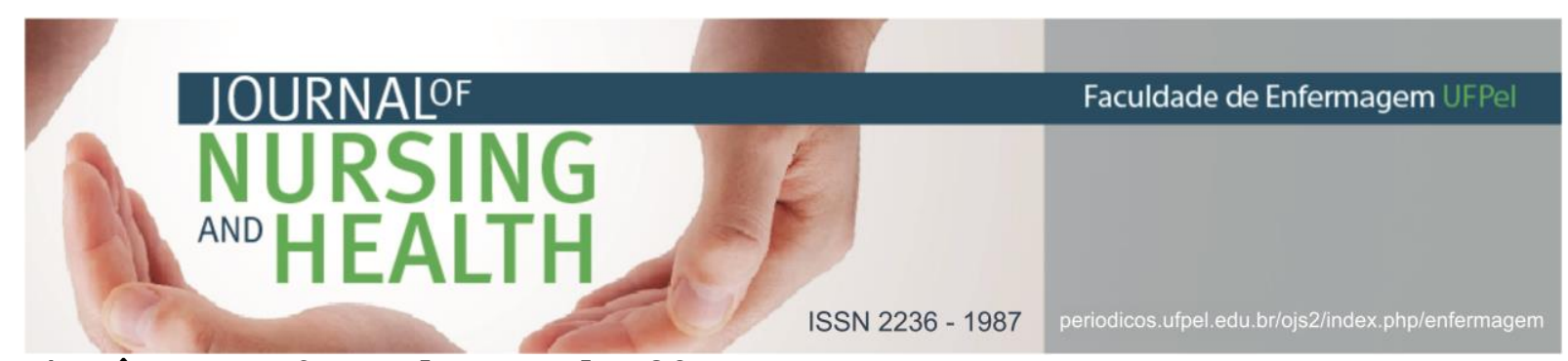

eletrônica enferm [Internet]. 2015 jul[acesso em 2015 nov 16]; 17(3). Disponível em:

https://www.fen.ufg.br/fen_revista/ v17/n3/pdf/v17n3a04.pdf

20. Maissiat GS, Lautert L, Dal Pai D, Tavares JP. Contexto de trabalho, prazer e sofrimento na atenção básica em saúde. Rev gaúch enferm. 2015 jun; 36(2):42-9.

Data da submissão: 2016-08-08 Aceito: 2016-12-26

Publicação: 2017-04-12 